\title{
Optimization of Nonvaporizing Nylon 6 Reactors with Stopping Conditions
}

\author{
AJAY K. RAY and SANTOSH K. GUPTA, ${ }^{*}$ Department of Chemical \\ Engineering, Indian Institute of Technology, Kanpur-208016, India
}

\begin{abstract}
Synopsis
In this study, optimal temperature profiles or histories $T(t)$ are obtained for nonvaporizing plug-flow or batch Nylon 6 reactors using the minimum principle. Two objective functions are studied, one in which the monomer conversion is maximized, and the other in which the undesirable cyclic dimer concentration in the product stream is minimized. The control variable, temperature, is constrained to lie between 220 and $270^{\circ} \mathrm{C}$ in order to ensure single-phase polymerization. The most significant difference between this study and earlier ones is that the residence or reaction time $t_{f}$ is not specified a priori, but is determined optimally by the use of a "stopping" condition such that the polymer product has a number-average chain length $\mu$, equal to some desired value $\mu_{n, d}$. This makes the algorithm considerably more complex, but the results are more meaningful. Qualitatively different optimal temperature profiles are obtained for the two objective functions studied, representing the complex interplay of several opposing factors in determining optimal conditions. This study also lays the foundation for even more complex, but relevant, optimization studies.
\end{abstract}

\section{INTRODUCTION}

In the last several years, there has been a spate of research activity in the area of polymerization reaction engineering in general ${ }^{1-4}$ and in the simulation on Nylon 6 polymerization ${ }^{5-9}$ in particular. These have been compiled in several recent books and review articles. In the field of Nylon 6 polymerization itself, there have been several review articles ${ }^{5-9}$ emphasizing various physicochemical aspects. An important point that emerges from a careful study of these reviews is that sufficiently precise experimental kinetic data are now available $e^{6,10-14}$ on the rates of the various main and side reactions taking place in Nylon 6 polymerization. What is necessary is to focus attention on the various physical processes occurring in industrial reactors, such as heat transfer, mixing and residence time distribution, and vaporization, and to develop strategies of optimal reactor operation and control. In fact, some amount of work along these lines has already been reported in the literature, ${ }^{10,15-22}$ but much more needs to be done in order that the design of Nylon 6 reactors be placed on a sound footing. In this paper, results of an optimization study on tubular Nylon 6 reactors with no vaporization of water are reported, and it is observed how different temperature profiles are required to have optimal operation of the reactor under different conditions.

*To whom correspondence should be addressed. This paper was revised when the second author was a Visiting Professor at the Department of Chemical Engineering, University of Notre Dame, Notre Dame, Indiana 46556.

Journal of Applied Polymer Science, Vol. 30, 4529-4550 (1985)

(C) 1985 John Wiley \& Sons, Inc.

CCC 0021-8995/85/124529-22\$04.00 
A few studies have been reported in the last few years in the area of optimization of Nylon 6 reactors. ${ }^{10,23-27}$ Hoftyzer et al..$^{27}$ were probably the first to carry out a detailed optimization study of Nylon 6 reactors. They used dynamic programming to determine the optimal temperature and water concentration (related to total applied pressure) histories required for producing polymer having a fixed value of the degree of polymerization in as short a reaction time as possible. Their study, therefore, is applicable for batch reactors since the pressure can be controlled more easily in these than in tubular reactors. It was found that high water concentrations and high temperatures are required in the beginning and low water concentrations and lower temperatures are required later on for optimal reactor operation, a conclusion consistent with intuitive expectations based on simulation studies of Nylon 6 polymerization. These results on batch reactor optimization suggested that optimal operation of tubular reactors could be achieved if one were to have two reactors in sequence, the first operating at a high water concentration, followed by one at a relatively lower water concentration. Several patented reactors, 22,28 including the VK column, do indeed operate under such conditions and use various techniques for removing the water after some residence time. Reimschuessel and Nagasubramanian ${ }^{10}$ studied sequences of such reactors (with instantaneous water removal between the two reactors) with a view to obtaining the best combination. Naudin ten Cate ${ }^{24}$ and Mochizuki and $\mathrm{Ito}^{23}$ used the minimum principle to find optimal temperature profiles in tubular reactors. Naudin ten Cate assumed a two-stage reactor, the first a well-mixed reactor at temperature $T_{o}$, with a residence time $t_{o}$, in which water is continuously evaporating. This is followed by a nonvaporizing tubular reactor having residence time $t_{f}-t_{o}$. The objective function to be minimized was the extraction value (unreacted monomer + undesirable higher cyclic oligomers), and an end-point constraint (degree of polymerization at $t_{f}$ equal to some fixed value) was applied. Optimal temperature profiles in the nonvaporizing tubular reactor were found for different values of $T_{o}$ and $t_{o}$. Mochizuki and Ito considered nonvaporizing reactors and obtained optimal temperature profiles with the unreacted monomer minimized. The degree of polymerization and the cyclic oligomer concentration in the final product were constrained to be equal to some fixed values. Their optimal temperature profile differed from that of Naudin ten Cate both because the objective function was different (Naudin ten Cate minimized the total cyclic oligomers, whereas Muchizuki and Ito constrained it to lie at a fixed value at the end of the reactor), and because the rate equations for the formation of the cyclic oligomers were different. In fact, both these groups of workers used semiempirical approximations for the rate of formation of cyclic oligomers. In addition, only semiquantitative results were presented for proprietary reasons.

Recently, Tai et al. ${ }^{13}$ have reported extensive experimental data on the rates of cyclic dimer formation. Some experimental results on the formation of the cyclic trimer, tetramer, and so on, have also been reported, ${ }^{14}$ but these have not yet been curve fit to give rate constants because of extreme theoretical problems. However, it has been shown ${ }^{14}$ that the formation of the cyclic dimer predominates and is, in practice, the more troublesome 
compound. Hence studies incorporating the cyclic dimer alone are sufficient to model the reactors. With this new information, it is possible to carry out optimization studies on tubular reactors that are far more meaningful than earlier studies. In addition, the advent of third-generation computers has facilitated the solution of relatively complex optimization problems, and it is anticipated that several optimization studies using different objective functions, constraints, and control variables will be reported in the near future. Indeed, some studies using the detailed and precise rate constants of Tai et al. ${ }^{13}$ have already been reported, ${ }^{25,26}$ using two objective functions, one that is more relevant to the design of new reactors ${ }^{25}$ and the other ${ }^{26}$, of interest to the optimal operation of an existing plant. In both these studies, as well as in all except one ${ }^{27}$ among the previous ones, however, the total reaction time $t_{f}$ is fixed, and it has been found that some values of $t_{f}$ give more optimal solutions (global optimal) than others. In fact, a definite need has been established to develop algorithms in which the reaction time $t_{f}$ is minimized simultaneously. This study describes such an algorithm.

\section{FORMULATION}

The detailed kinetic scheme for Nylon 6 polymerization is given ${ }^{8,9}$ in Table I, along with relevant rate and equilibrium constants. This represents the most recent and precise information on Nylon 6 polymerization available in the literature. This scheme includes the three major reactions: ring

TABLE I

Kinetic Scheme for Nylon 6 Polymerization ${ }^{a}$

1. Ring opening:

$$
C_{1}+W \underset{k_{1}^{\prime}=k_{1} / K_{1}}{\stackrel{k_{1}}{\rightleftharpoons}} S_{1}
$$

2. Polycondensation:

$$
S_{n}+S_{m} \underset{k_{2}^{\prime}=k_{2} / K_{2}}{\stackrel{k_{2}}{\rightleftharpoons}} S_{n+m}+W
$$

3. Polyaddition:

$$
S_{n}+C_{1} \underset{k_{3}^{\prime}=k_{3} / k_{3}}{\stackrel{k_{3}}{=}} S_{n+1}
$$

4. Reaction with monofunctional acid:

$$
S_{n}+A_{m} \underset{k_{2}^{\prime}}{\stackrel{k_{2}}{\rightleftharpoons}} A_{n+m}+W
$$

5. Ring opening of cyclic dimer:

$$
C_{2}+W \stackrel{k_{4}}{\underset{k_{4}^{\prime}=k_{4} / K_{4}}{\rightleftharpoons}} S_{2}
$$

6. Polyaddition of cyclic dimer:

$$
S_{n}+C_{2} \underset{k_{5}^{\prime}=k_{5} / K_{5}}{\stackrel{k_{5}}{\rightleftharpoons}} S_{n+2}
$$


TABLE I

Kinetic Scheme for Nylon 6 Polymerization ${ }^{\mathrm{a}}$ (Continued)

Rate and equilibrium constants:

$$
\begin{aligned}
k_{i} & =A_{i}^{o} \exp \left(-E_{i}^{o} / R T\right)+A_{i}^{c} \exp \left(-E_{i}^{c} / R T\right) \sum_{n=1}^{\infty}\left(\left[A_{n}\right]+\left[S_{n}\right]\right) \\
& =k_{i}^{o}+k_{i}^{c} \sum_{n=1}^{\infty}\left(\left[S_{n}\right]+\left[A_{n}\right)\right. \\
K_{i} & =\exp \left\{\left(\Delta S_{i}-\Delta H_{i} / T\right) / R\right\} \quad i=1,2, \ldots, 5
\end{aligned}
$$

\begin{tabular}{ccccccc}
\hline & $\begin{array}{c}A_{i}^{o} \\
(\mathrm{~kg} / \mathrm{mol} \cdot \mathrm{h})\end{array}$ & $\begin{array}{c}E_{i}^{o} \\
(\mathrm{cal} / \mathrm{mol})\end{array}$ & $\begin{array}{c}A_{i}^{\mathrm{c}} \\
\left(\mathrm{kg}^{2} / \mathrm{mol}^{2} \cdot \mathrm{h}\right)\end{array}$ & $\begin{array}{c}E_{i}^{c} \\
(\mathrm{cal} / \mathrm{mol})\end{array}$ & $\begin{array}{c}\Delta H_{i} \\
(\mathrm{cal} / \mathrm{mol})\end{array}$ & $\begin{array}{c}\Delta S_{i} \\
(\mathrm{eu})\end{array}$ \\
\hline 1 & $5.9874 \times 10^{5}$ & $1.9880 \times 10^{4}$ & $4.3075 \times 10^{7}$ & $1.8806 \times 10^{4}$ & $1.9180 \times 10^{3}$ & $-7.8846 \times 10^{0}$ \\
2 & $1.8942 \times 10^{10}$ & $2.3271 \times 10^{4}$ & $1.2114 \times 10^{10}$ & $2.0670 \times 10^{4}$ & $-5.9458 \times 10^{3}$ & $9.4374 \times 10^{-1}$ \\
3 & $2.8558 \times 10^{9}$ & $2.2845 \times 10^{4}$ & $1.6377 \times 10^{10}$ & $2.0107 \times 10^{4}$ & $-4.0438 \times 10^{3}$ & $-6.9457 \times 10^{0}$ \\
4 & $8.5778 \times 10^{11}$ & $4.2000 \times 10^{4}$ & $2.3307 \times 10^{12}$ & $3.7400 \times 10^{4}$ & $-9.6000 \times 10^{3}$ & $-1.4520 \times 10^{1}$ \\
5 & $2.5701 \times 10^{8}$ & $2.1300 \times 10^{4}$ & $3.0110 \times 10^{9}$ & $2.0400 \times 10^{4}$ & $-3.1691 \times 10^{3}$ & $5.8265 \times 10^{-1}$ \\
\hline
\end{tabular}
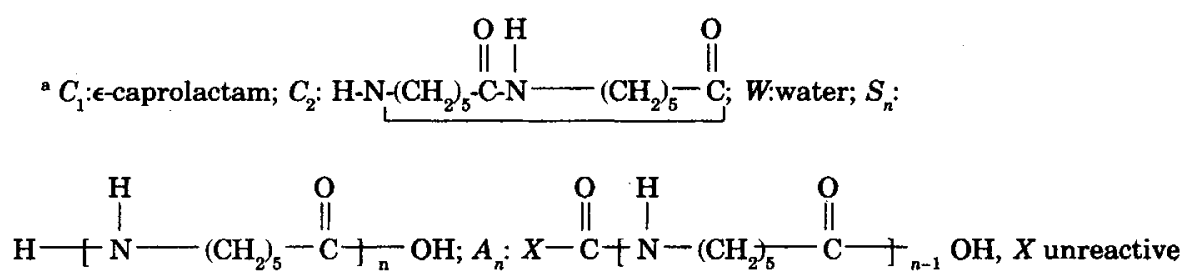

group; $T=$ temperature; $R=$ gas constant.

opening, polycondensation, and polyaddition. In addition to these it incorporates the two reactions involving the cyclic dimer $C_{2}$. The reactions with only the cyclic dimer are included because the rate constants for the actions of higher cyclic oligomers are not yet known precisely. Recently; however, Tai and Tagawa ${ }^{14}$ have reported some experimental data on the buildup of various cyclic oligomers with time, and this can be used to obtain the rate constants. In any case, it has been found experimentally that the formation of the cyclic dimer predominates, and very little error is expected because of this simplification. Reactions with monofunctional acids $A_{n}$ are also included because these increase the rate of polymerization and also control the molecular weight of the polymer formed. Other side reactions, such as decarboxylation, desamination, and peroxidation of caprolactam, are not included in order to keep the analysis simple. The corresponding mass balance equations for nonvaporizing, plug flow, or batch reactors are given in Reference 25 and can be written in the following matrix notation:

$$
\frac{d x_{i}}{d t}=f_{i}(\mathbf{x}, \mathbf{u}) \quad i=1,2, \ldots, n
$$


where the state variables are given by

$$
\begin{aligned}
\mathbf{x}^{T} & =\left[x_{1}, x_{2}, \ldots, x_{10}\right] \\
& \equiv\left[\left[C_{1}\right],\left[S_{1}\right], \mu_{0}, \mu_{1}, \mu_{2},\left[C_{2}\right],[W], \mu_{1}^{\prime}, \mu_{2}^{\prime},\left[A_{1}\right]\right]
\end{aligned}
$$

In eq. 2 , the brackets represent concentrations in moles per kilogram mixture, $\mu_{k}$ and $\mu_{k}^{\prime}$ represent the moments of the bifunctional molecular species $S_{n}$ and the monofunctional species $A_{n}$, respectively:

$$
\begin{aligned}
& \mu_{k}=\sum_{n=1}^{\infty} \quad n^{k} \quad\left[S_{n}\right] \\
& \mu_{k}^{\prime}=\sum_{n=1}^{\infty} n^{k} \quad\left[A_{n}\right]
\end{aligned}
$$

and $\mathbf{u} \equiv\left[u_{1}, u_{2}, \ldots u_{1}\right]$ are the l-control variables. In this study, there is only one-control variable, temperature $T(t)$. As discussed in earlier simulation studies, ${ }^{20,21,29}$ closure conditions are required in order to solve the mass balance equations. These are given by

$$
\begin{gathered}
{\left[S_{2}\right]=\left[S_{3}\right]=\left[S_{1}\right]} \\
\mu_{3}=\frac{\mu_{2}\left(2 \mu_{2} \mu_{0}-\mu_{1}^{2}\right)}{\mu_{1} \mu_{0}} \\
\mu_{3}^{\prime}=\frac{\mu_{2}^{\prime}\left(2 \mu_{2}^{\prime} \mu_{0}^{\prime}-\mu_{1}^{\prime 2}\right)}{\mu_{1}^{\prime} \mu_{0}^{\prime}}
\end{gathered}
$$

These closure equations have been demonstrated to be extremely successful ${ }^{20,30}$ in predicting the moments for both batch (or plug flow) reactors as well as continuous flow stirred tank reactors and give results that match those obtained from a detailed integration of mass balance equations of the individual species. ${ }^{31,32}$

Two different objective functions $I$ have been selected in this work to enable a comparative study:

$$
\begin{aligned}
& \operatorname{Min} I(T(t))=\alpha_{1}\left[C_{1}^{2}\right]_{t_{f}} \\
& \operatorname{Min} I(T(t))=\alpha_{2}\left[C_{2}\right]_{t_{f}}
\end{aligned}
$$

where $T(t)$ is the temperature history or profile (temperature as a function of time in batch reactors or of reaction time in tubular reactors) to be determined optimally so that $I$ is minimized, and $\alpha_{1}$ and $\alpha_{2}$ are weighting 
factors. It is shown subsequently in this paper that the use of $\left[C_{1}\right]_{t_{f}}$ instead of $\left[C_{1}\right]_{t_{f}}^{2}$ in eq. (5a) leads to identical final results. Similarly, it is found that the weightage factors $\alpha_{1}$ and $\alpha_{2}$ in these objective functions are not really required, since the optimal temperature profiles are independent of their values. The total residence or reaction time $t_{f}$ is not fixed a priori, as in earlier optimization studies, ${ }^{10,23-26}$ but is determined optimally by the algorithm itself. Both the optimization problems are solved subject to the "stopping" condition

$$
\mathrm{p}\left(\mathbf{x}\left(t_{f}\right), t_{f}\right) \equiv \frac{\mu_{n, t_{f}}-\mu_{n, d}}{\mu_{n, d}}=0
$$

which ensures that the product from the reactor has a certain "desired" or fixed value $\mu_{n, d}$ of the number-average chain length or degree of polymerization $D P=\mu_{n} \equiv\left(\mu_{1}+\mu_{1}^{\prime}\right) /\left(\mu_{0}+\mu_{0}^{\prime}\right)$. The total residence time $t_{f}$ is selected such that the stopping condition is satisfied. End-point constraints of the following general type can also be considered simultaneously:

$$
\psi_{i}\left(\mathbf{x}\left(t_{f}\right), t_{f}\right)=0 \quad i=1,2, \ldots, m
$$

Several sets of meaningful optimization problems can be formulated within the above framework. Two interesting possibilities could be the following. Objective function:

$$
\operatorname{Min} I(T(t))=\alpha_{1}\left[C_{1}\right]_{t_{f}}^{2} \quad \text { or } \quad \alpha_{2}\left[C_{2}\right]_{t_{f}}
$$

Stopping condition $\rho\left(\mathbf{x}\left(t_{f}\right), t_{f}\right)=0$ :

$$
\frac{\mu_{n, t}-\mu_{n, d}}{\mu_{n, d}}=0 \quad \text { both cases }
$$

End-point constraint $\psi_{1}\left(\mathbf{x}\left(t_{f}\right), t_{f}\right)=0$ :

$$
\left[C_{2}\right]_{t_{f}}-\left[C_{2}\right]_{d}=0 \quad \text { or } \quad\left[C_{1}\right]_{t_{f}}-\left[C_{1}\right]_{d}=0
$$

Constraints on $T$ :

$$
220^{\circ} \mathrm{C} \leqslant \mathrm{T} \leqslant 270^{\circ} \mathrm{C} \quad \text { both cases }
$$

where $\left[C_{1}\right]_{d}$ and $\left[C_{2}\right]_{d}$ represent the desired concentrations of $C_{1}$ and $C_{2}$ in the product stream.

It may be emphasized that the two problems discussed in eq. (8) differ significantly from those solved by earlier workers, ${ }^{23,24}$ who assumed a fixed 
value of $t_{f}$. Since the flexibility of choosing the reaction time optimally is usually present in the design of new reactors, the solution of the problems in eq. (8) is of considerable industrial interest for such situations. The earlier studies of Mochizuki and Ito $^{23}$ and of Naudin ten Cate ${ }^{24}$ are of more relevance to the optimal operation of existing reactors.

The algorithm for the general optimization problem presented in eq.(8) with stopping conditions as well as end-point constraints is summarized in Table II. This has been compiled from Lapidus and Luus ${ }^{33}$ and Bryson and $\mathrm{Ho}^{34}$ and incorporates some minor corrections. In order to solve this problem, two sets of adjoint functions $\lambda_{i}^{I}$ and $\lambda_{i}(i=1,2, \ldots, n)$ have to be defined. The differential equations for these functions are identical in form and are given in Table II in matrix form (or in Refs. 25 and 26 in more expanded notation). However, their numerical values at any time $t$ will be different since they have different boundary conditions at $t=t_{f}$.

TABLE II

Equations for Optimality with End-Point Constraints and Stopping Conditions

1. Objective function:

$$
\operatorname{Min} I\left(\mathbf{x}\left(t_{f}\right), t_{f}\right)
$$

2. Mass balance (state variable) equations:

$$
\frac{d \mathbf{x}}{d t} \equiv\left[\begin{array}{c}
d x_{1} / d t \\
d x_{2} / d t \\
\cdot \\
\cdot \\
d x_{n} / d t
\end{array}\right]=\mathbf{f}(\mathbf{x}(t), \mathbf{u}(t)) \equiv\left[\begin{array}{c}
f_{1}(\mathbf{x}, \mathbf{u}) \\
f_{2}(\mathbf{x}, \mathbf{u}) \\
\cdot \\
\cdot \\
f_{n}(\mathbf{x}, \mathbf{u})
\end{array}\right]
$$

with

$$
\mathbf{u}^{T}(t) \equiv\left[u_{1}, u_{2}, \ldots, u_{t}\right]
$$

3. End-point constraints:

$$
\psi\left(\mathbf{x}\left(t_{f}\right), t_{f}\right) \equiv\left[\begin{array}{c}
\psi_{1}\left(\mathbf{x}\left(t_{f}\right), t_{f}\right) \\
\psi_{2}\left(\mathbf{x}\left(t_{f}\right), t_{f}\right) \\
\vdots \\
\cdot \\
\psi_{m}\left(\mathbf{x}\left(t_{f}\right), t_{f}\right)
\end{array}\right]=0
$$

4. Stopping condition:

$$
\rho\left(\mathbf{x}\left(t_{f}\right), t_{f}\right) \equiv \rho\left[x_{1}\left(t_{f}\right), x_{2}\left(t_{f}\right), \ldots, x_{n}\left(t_{f}\right) ; t_{f}\right]=0
$$

5. Constraints on $\mathbf{u}$ :

$$
\mathbf{u}_{\min } \leq \mathbf{u} \leq \mathbf{u}_{\max }
$$


TABLE II. (continued from previous page)

6. Adjoint function equations:

$$
\text { a. }\left.\frac{d \lambda^{I}(t)}{d t}\right|_{(n \times 1)} \equiv \frac{d}{d t}\left[\begin{array}{c}
\lambda_{1} \\
\lambda_{2} \\
\cdot \\
\cdot \\
\lambda_{n}^{I}
\end{array}\right]=-\mathbf{A}^{T}(t) \lambda^{I}(t) ; \quad \lambda^{I}\left(t_{f}\right)=\left(\frac{\partial I}{\partial \mathbf{x}}\right)_{t=t_{f}}
$$

where

$$
\mathbf{A}^{T}(t)=\left(\frac{\partial \mathbf{f}^{T}}{\partial \mathbf{x}}\right)_{n \times n} \equiv\left[\begin{array}{c}
\frac{\partial f_{1}}{\partial x_{1}}, \frac{\partial f_{2}}{\partial x_{1}}, \ldots, \frac{\partial f_{n}}{\partial x_{1}} \\
\frac{\partial f_{1}}{\partial x_{2}}, \frac{\partial f_{2}}{\partial x_{2}}, \ldots, \frac{\partial f_{n}}{\partial x_{2}} \\
\cdot \\
. \\
\frac{\partial f_{1}}{\partial x_{n}}, \frac{\partial f_{2}}{\partial x_{n}}, \ldots, \frac{\partial f_{n}}{\partial x_{n}}
\end{array}\right]
$$

b. $\left.\frac{d \lambda^{\psi}(t)}{d t}\right|_{n \times m} \equiv \frac{d}{d t}\left[\begin{array}{c}\lambda_{1}^{\psi 1}, \lambda_{1}^{\psi 2}, \ldots, \lambda_{1}^{\psi m} \\ \lambda_{2}^{\psi_{1}}, \lambda_{2}^{\psi_{2}}, \ldots, \lambda_{2}^{\psi m} \\ \cdot \\ \cdot \\ \lambda_{h}^{\psi_{1}}, \lambda_{h 2}^{\psi_{2}}, \ldots, \lambda_{h}^{\psi_{m}}\end{array}\right]=-\mathbf{A}^{T}(t) \lambda^{\psi}(t) ; \lambda^{\psi}\left(t_{f}\right)=\left(\frac{\partial \psi^{T}}{\partial \mathbf{x}}\right)_{t=t f}$

7. Increment in $\mathbf{u}(t)$;

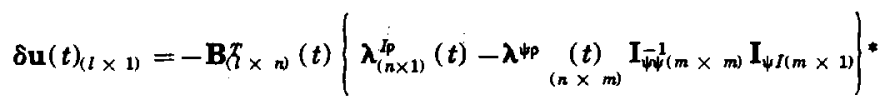

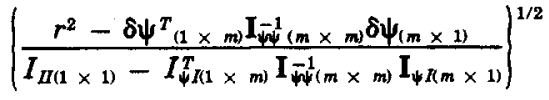

$$
\begin{aligned}
& +\mathbf{B} K_{\times n)}(t) \lambda(\psi p \times m)(t) \mathbf{I}_{n \psi(m \times m)} \delta \psi_{(m \times 1)}
\end{aligned}
$$

where

$$
\begin{aligned}
\mathbf{I}_{\psi \psi(m \times m)} & =\int_{0}^{t f} \lambda_{(m \times n)}^{\psi p}(t)^{T} \mathbf{B}_{(n \times l)}(t) \mathbf{B} \hbar_{\times n)}(t) \lambda_{(n \times m)}^{\psi p}(t) d t \\
\mathbf{I}_{\psi /(m \times 1)} & =\int_{0}^{t f} \lambda_{(m \times n)}^{\psi p}(t)^{T} \mathbf{B}_{(n \times l)}(t) \mathbf{B} \lambda_{\times n)}(t) \lambda_{(h \times 1)}^{(p}(t) d t
\end{aligned}
$$


TABLE II. (continued from previous page)

$$
\begin{aligned}
& I_{I I(1 \times 1)}=\int_{0}^{t f} \lambda_{(1 \times n)}^{L_{p}}(t)^{T} \mathbf{B}_{(n \times n)}(t) \mathbf{B}_{(l \times n)}^{T}(t) \lambda_{(n \times 1)}^{L_{p}} d t \\
& \lambda_{(n \times 1)}^{\phi}(t)=\lambda_{(n \times 1)}^{I}(t)-\lambda_{(n \times 1)}^{\rho}(t)\left[\frac{\frac{\partial I}{\partial t}+\left(\frac{\partial I}{\partial \mathbf{x}}\right) \mathbf{r}_{\mathbf{f}}}{\frac{\partial \rho}{\partial t}+\left(\frac{\partial \rho}{\partial \mathbf{x}}\right) \pi_{\mathbf{f}}}\right]_{t=t_{f}} \\
& \lambda_{(n \times m)}^{\psi p}=\lambda_{(n \times m)}^{(t)}-\lambda_{(n \times 1)}^{p}(t)\left[\frac{\left(\frac{\partial \psi}{\partial t}+\left(\frac{\partial \psi^{T}}{\partial x}\right) r_{f}\right\}_{(1 \times m)}^{T}}{\frac{\partial \rho}{\partial t}+\left(\frac{\partial \rho}{\partial \mathbf{x}}\right)_{f}^{T}}\right] t=t_{i}
\end{aligned}
$$

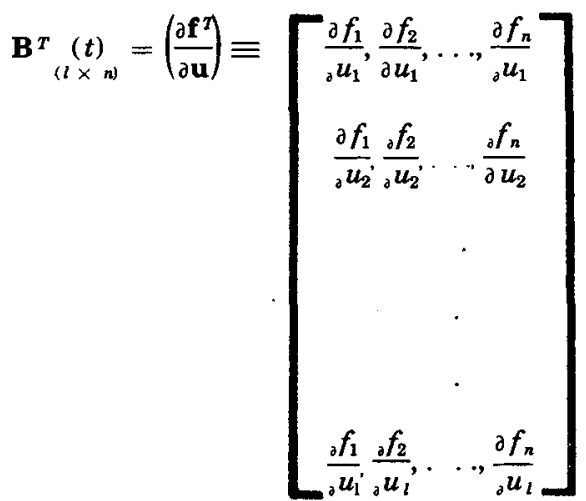

8. Increment $\delta \psi$ :

$$
\delta \psi_{(m \times 1)}=-\epsilon \psi\left(t_{f}\right)
$$

"Subscripts in brackets, e.g., $(n \times 1)$, indicate order of the matrix.

Our initial attempts at solving the two problems discussed in eq. (8) proved unsuccessful because of severe numerical problems. Apparently, such numerical instabilities do not arise in the optimization of problems with $t_{f}$ fixed a priori. ${ }^{23,24}$ Because of the considerable interest and importance of the problems with floating $t_{f}$, it was decided to omit the end-point constraints [eq. (8c)] and study the following two simplified problems:

Problem I:

$$
\begin{array}{ll}
\operatorname{Min} I=\alpha_{1}\left[C_{1}\right]_{t_{f}}^{2} & \text { Min } I=\alpha_{2}\left[C_{2}\right]_{t_{f}} \\
\frac{\mu_{n, t_{f}}-\mu_{n, d}}{\mu_{n, d}}=0 & \frac{\mu_{n t_{f}}-\mu_{n, d}}{\mu_{n, d}}=0 \\
220^{\circ} \mathrm{C} \leqslant T \leqslant 270^{\circ} \mathrm{C} & 220^{\circ} \mathrm{C} \leqslant T \leqslant 270^{\circ} \mathrm{C}
\end{array}
$$


with $t_{f}$ determined optimally using the stopping condition of eq. (9b). This simplified problem, although less interesting industrially, will help develop numerical algorithms and lead to insights that may prove in the future to be of immense value in solving the problem discussed in eq. (8).

For the simplified case considered in this paper, the variables $\mathbf{I}_{\psi \psi}, \mathbf{I}_{\psi I}$, and $\delta \psi$ in Table II are zero and the following equation for $\delta \mathbf{u}$ is to be used:

$$
\delta \mathbf{u}(t)=-\left(\frac{\mathbf{r}^{2}}{\mathbf{I}_{\text {II }}}\right)^{1 / 2} \mathbf{B}^{T}(t) \lambda^{I_{p}}(t)
$$

The numerical procedure to be followed is described for this special case of no end-point constraints.

(1) An initial temperature history $T_{\mathrm{o}}(t)$, is selected, that is, the temperature at, say, $t=0,0.2,0.4, \ldots, \mathrm{h}$ is chosen. This is usually taken as isothermal. The state variable equations are then integrated numerically in the forward direction, using the fourth-order Runge Kutta technique and the known initial values $\mathbf{x}(0)$. The value of $\Delta t$ used is smaller than $0.2 \mathrm{~h}$, say, $0.04 \mathrm{~h}$, and so a linear interpolation of temperature is required. Thus, there are two time grids-one spaced $0.04 \mathrm{~h}$ apart and another $0.2 \mathrm{~h}$ apart. This is necessary in order to keep storage requirements within reasonable limits. The forward integration is done till the stopping condition of eq. (6) is satisfied within some tolerance limit determined interactively on a computer terminal (usually such that $\left|\mu_{n, t_{f}}-\mu_{n, d}\right| \leqslant \epsilon_{1}$ ). This defines a value of $t_{f}$ corresponding to the assumed $T_{o}(t)$. While doing the forward integration, the values of $\partial f_{i} / \partial T$ are also computed at $t=0,0.2,0.4, \ldots, t_{f} \mathrm{~h}$ using the equations in Reference 25. The values of $T, k_{i} \mathrm{~s}, K_{i}$, and $\partial f_{i} / \partial T$ are stored after every $0.2 \mathrm{~h}$ and at $t_{f}$. The objective function $I$ is evaluated once $t_{f}$ is determined.

(2) With the forward integration complete, the adjoint variable equations (Ref. 26) are integrated in the backward direction, that is, from $t=t_{f}$ to $t=0$, using the fourth-order Runge Kutta method with $\Delta t=0.04 \mathrm{~h}$ and the boundary conditions at $t=t_{f} . \lambda^{\lambda P}(t)$ and the contribution from $t_{f}$ to $t$ in $I_{\mathrm{II}}$ are computed. In carrying out the backward integration, the stored rate and equilibrium constants and $\partial f_{i} / \partial T$ (at interals of $0.2 \mathrm{~h}$ ) are used. $\lambda^{I P}(t)$ is again stored at values of $t=0.2 n \mathrm{~h}$ (where $n$ is an integer) and at $t_{f}$ for use in the next step of the algorithm.

(3) With $I_{\mathrm{n}}$ now known, a value of $r$ is selected as discussed later, and $\delta T$ is calculated at $0.2 n \mathrm{~h}(n=0,1,2, \ldots)$ and at $t_{f}$, using eq. (10). Stored values of $\partial f_{i} / \partial T$ and $\lambda^{I_{p}}$ are used for this purpose. The new temperature profile is then obtained using

$$
T_{\text {new }}(t)=T_{\text {old }}(t)+\delta T(t)
$$

This completes one iteration of computations.

(4) Steps (1) to (3) are repeated until $I$ becomes constant or there is no change in the temperature profile. 
In the presence of end-point constraints of the type given by eq. (7), a value of $\epsilon$ (see Table II) must also be selected and the adjoint variables $\lambda^{* p}$ and the integrals $I_{\psi \psi}$ and $\mathbf{I}_{\psi 1}$ computed. Equation (11) can then be used to improve upon the assumptions of $T(t)$, provided the more general expression for $\delta T(t)$ from Table II is used instead of eq. (10).

In obtaining the optimal temperature profiles, the control variable (temperature) is constrained to lie between two limiting values

$$
220^{\circ} \mathrm{C} \leqslant T \leqslant 270^{\circ} \mathrm{C}
$$

The lower of these values represents the melting point of the polymer, and the upper limit represents the approximate boiling point of (pure) caprolactam at atmospheric conditions. Thus, eq. (12) ensures single-phase polymerization.

Several checks were used to ensure that the results are free of errors. The computer program gave results that were identical to those obtained earlier ${ }^{20}$ when run in the simulation mode at isothermal conditions. Also, the program gave similar optimal temperature profiles as those obtained earlier ${ }^{26}$ when the objective function was chosen as $I=\left[C_{1}\right]_{t}^{2}$, two end-point constraints were used, namely, $\mu_{n, t_{f}}-\mu_{n, d}=0$ and $\left[C_{2}\right]_{t_{f}}-\left[C_{2}\right]_{d}=0$, and $t_{f}$ was fixed. All these checks gave confidence regarding the correctness of the computer program.

\section{RESULTS AND DISCUSSIONS}

Optimal temperature profiles have been determined using the algorithm described above for the following reference values of the physical or design variables encountered in the analysis:

$$
\begin{aligned}
{\left[C_{1}\right]_{o} } & =8.8 \mathrm{~mol} / \mathrm{kg} \\
{\left[W_{o}\right.} & =0.16 \mathrm{~mol} / \mathrm{kg} \\
{\left[A_{1}\right]_{o} } & =0.0 \\
\mu_{n, d} & =180
\end{aligned}
$$

The values of some of the computational parameters used were as follows:

$$
\begin{array}{rl}
I=\alpha_{1}\left[C_{1}\right]_{t_{f}}^{2} & I=\alpha_{2}\left[C_{2}\right]_{t_{f}} \\
\Delta t=0.04 \mathrm{~h} & 0.04 \mathrm{~h} \\
T_{o}(t)=250^{\circ} \mathrm{C} & 245^{\circ} \mathrm{C} \\
\alpha_{1}=1.0 & \alpha_{2}=1.0 \\
\mathrm{r}=5.0 \mathrm{~h}^{1 / 2}-K & 5.0 \mathrm{~h}^{-1}-K \\
\epsilon_{1}=0.1 & 0.1-0.5
\end{array}
$$


Figure 1 shows how the temperature history or profile changes with the iteration number and finally converges in 33 iterations to the optimal, when $I=\left[C_{1}\right]_{t r}^{2}$ It must be pointed out that, in this case, there is no change in the temperature profiles obtained in the 32nd and 33rd iterations. The conditions are as in eqs. (13) and (14). The computer time on a DEC 1090 for about 32 iterations was about $71 / 2 \mathrm{~min}$. A step change in the temperature is indicated to ensure optimal operation, with the maximum permissible temperature at the beginning and the minimum value near the end. Such an optimal temperature profile can be intuitively justified from a study of Figures 2 and 3 , which give simulation results for isothermal reactors. It can be observed from these diagrams that in order to get the highest conversion and the highest $\mu_{n}$ in as rapid a manner as possible, one must use the highest possible temperature. However, Figure 2 shows that a $\mu_{m, t_{f}}$ of 180 will not be achieved if a temperature of $270^{\circ} \mathrm{C}$ is used throughout the reactor, and one must lower the temperature at some stage in the reactor in order to get the high values of $\mu_{n}$ required. Our optimal temperature profile is thus justified. It is observed from Figures 2 and 3 that in order to get a polymer with a value of $\mu_{n, t_{f}}$ of 140 with the highest caprolactam conversion and in the shortest reaction time, one must use a temperature of $270^{\circ} \mathrm{C}$ throughout. Our program does indeed predict this, as discussed later.

Figure 4 shows optimal temperature profiles for the objective function $I=\left[C_{2}\right]_{t r}$ Qualitatively different results are observed in this case than for $I=\left[C_{1}\right]_{t_{f}}^{2}$ using conditions given in eqs. (13) and (14). It was observed that the computed profiles oscillate slightly (by about $2^{\circ} \mathrm{C}$ ) with iteration number, and so one can, at best, determine an optimal zone for the temperature profile using this first-order numerical method. More sophisticated second-order numerical techniques ${ }^{33,34}$ must be used in order to get better

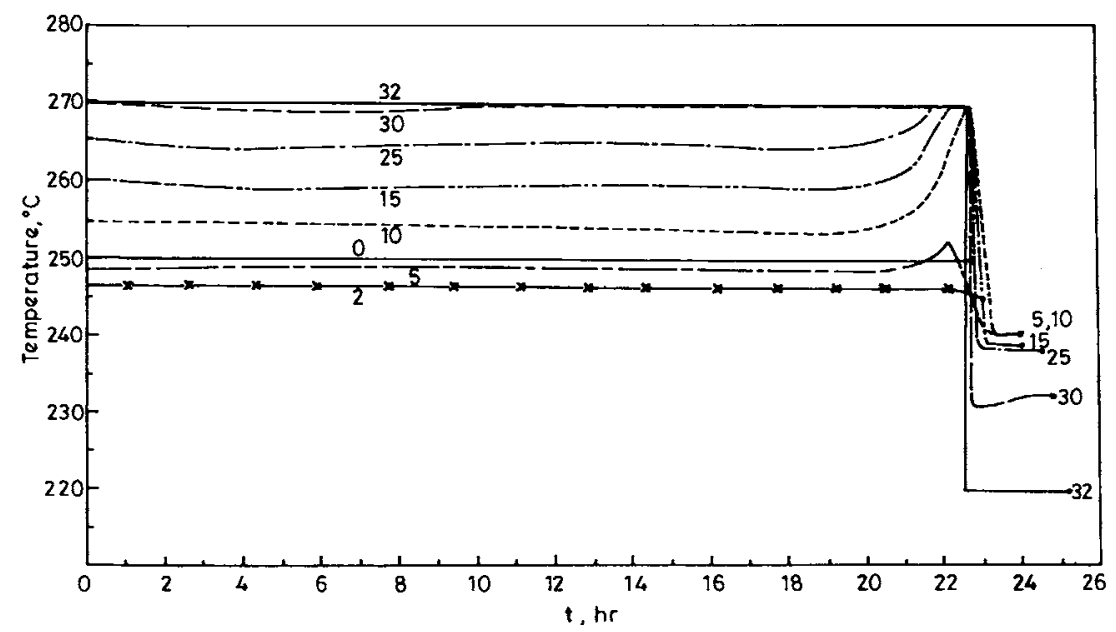

Fig. 1. Convergence of the computed temperature profiles for $I=\left[C_{1}\right]_{t}^{2}$ toward the optimal. Conditions as in eqs. (13) and (14). Iteration numbers indicated. For the optimal case, $t_{f}=25.3$ $\mathrm{h}$, caprolactam conversion $=91.6 \%,\left[C_{2}\right]_{t_{f}}=0.0310 \mathrm{~mol} / \mathrm{kg}$. 


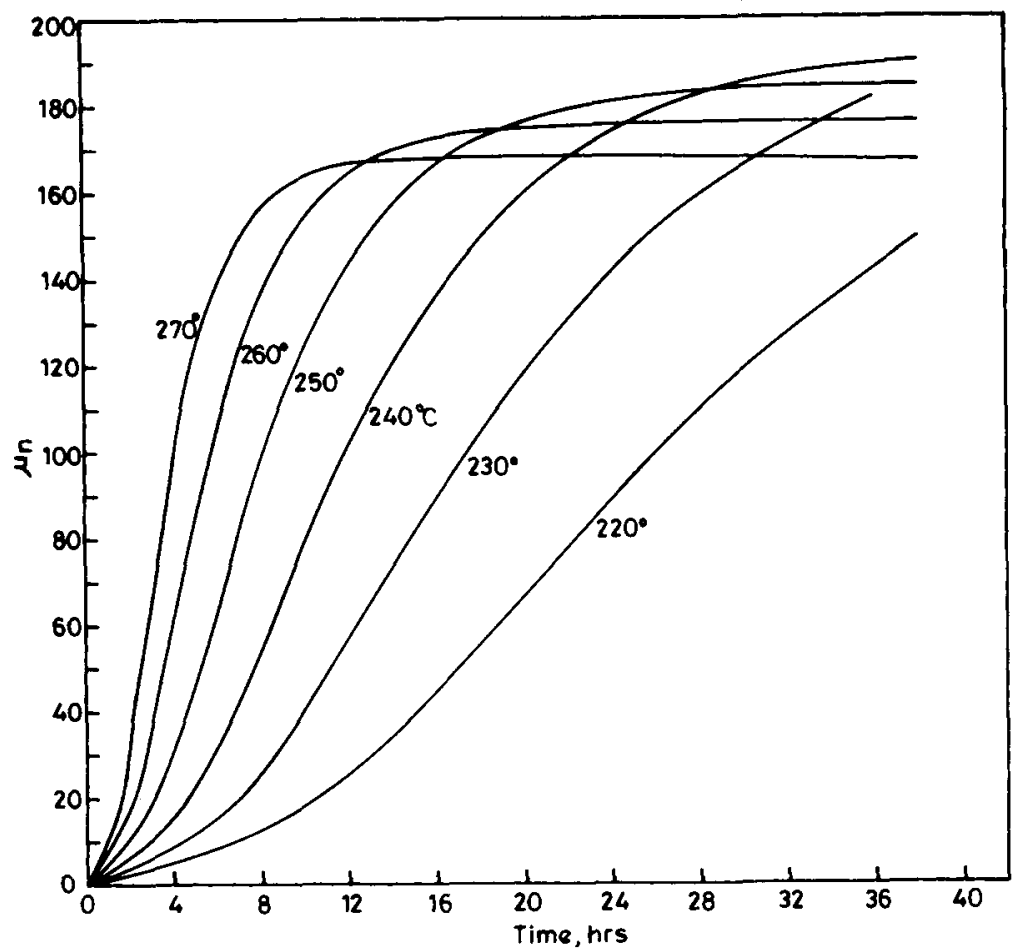

Fig. 2. Simulation results for $\mu_{n}(t)$ for isothermal, nonvaporizing reactors. $[W]_{o}=0.16$ $\mathrm{mol} / \mathrm{kg}$; temperatures $\left({ }^{\circ} \mathrm{C}\right)$ indicated.

convergence. Several attempts at reducing the width of this optimal temperature zone by changing the computational parameters failed, and so it is inferred that this is because of the inherent weakness of the first-order technique ${ }^{33-35}$ Figure 5 shows simulation results on $\left[C_{2}\right]$ for isothermal, nonvaporizing reactors. A close scrutiny of Figures 1 through 5 reveals an interesting analysis of the optimal temperature profiles. It is seen that the

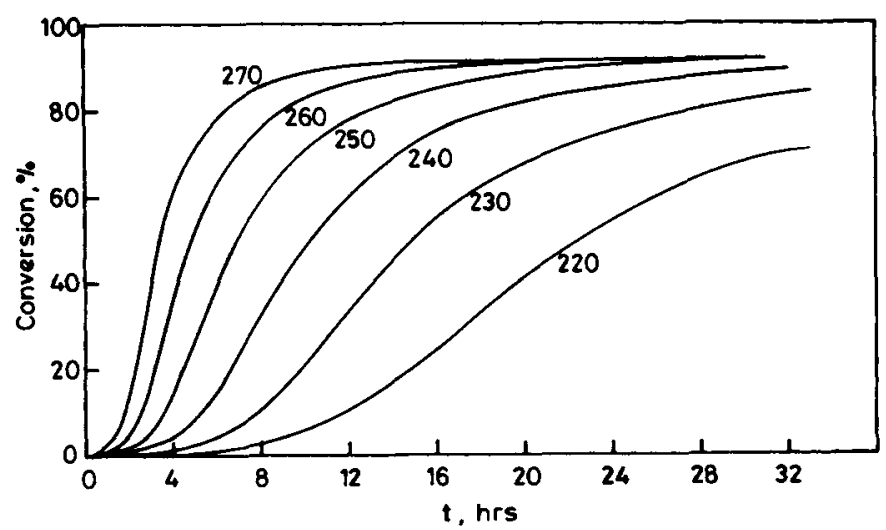

Fig. 3. Simulation results for conversion for isothermal nonvaporizing reactors. $[W]_{o}=0.16 \mathrm{~mol} / \mathrm{kg}$. Temperatures $\left({ }^{\circ} \mathrm{C}\right)$ indicated. 


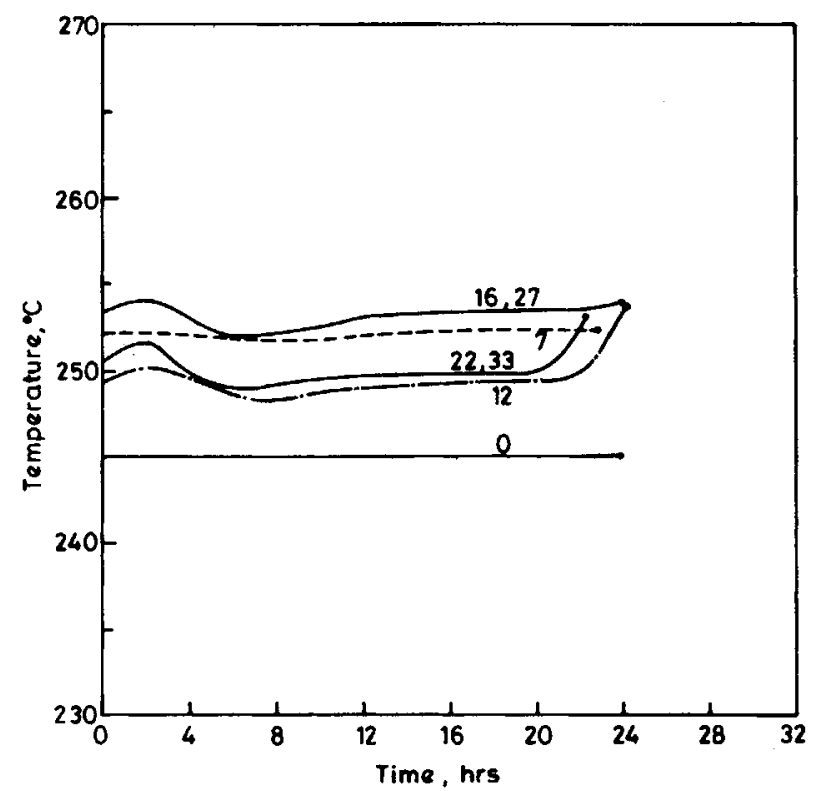

Fig. 4. Convergence of the computed temperature profiles for $I=\left[C_{2}\right]_{t}$ toward the optimal. Conditions as in eqs. (13) and (14). Iteration number indicated. Results oscillate between profiles of iteration 28 and 32 for which, respectively, $\left[C_{2}\right]_{t_{f}}=0.0172$ and $0.0179 \mathrm{~mol} / \mathrm{kg} ; t_{f}=22.44$ and $22.36 \mathrm{~h}$; caprolactam conversion $=89.85$ and $90.18 \%$.

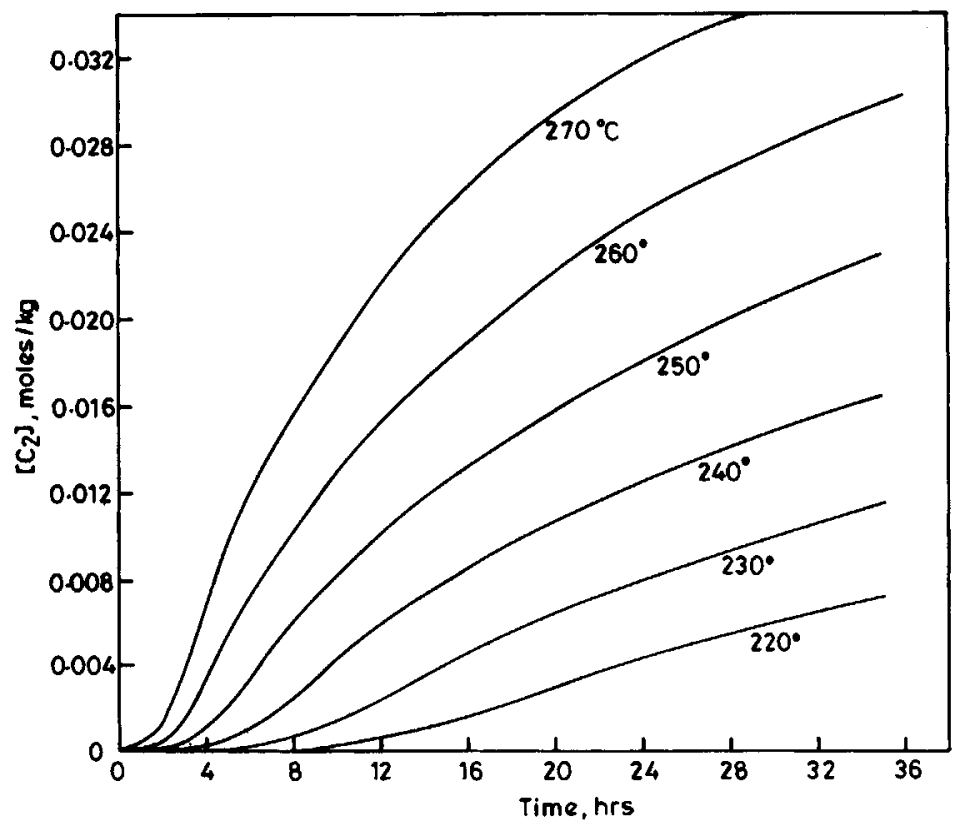

Fig. 5. Simulation results for $\left[C_{2}\right]$ for isothermal, nonvaporizing reactors. $[W]_{o}=0.16 \mathrm{~mol} /$ kg. Temperatures $\left({ }^{\circ} \mathrm{C}\right)$ indicated. 
use of high initial temperatures leads to a faster conversion of the caprolactam and to a faster increase in $\mu_{n}$ and so is desirable when, $I=\left[C_{1}\right]_{t_{r}}^{2}$ In contrast, use of high initial temperatures is not necessarily indicated when $I=\left[C_{2}\right]_{t_{f}}$ because, even though it leads to a faster increase in $\mu_{n}$ and thus helps lower reaction times, it also simultaneously leads to a higher formation of $C_{2}$ and so is undesirable from the point of view of the objective function. This study thus shows the complex interplay of the various terms ( $\left[C_{2}\right], \mu_{n}$, conversion, and $t_{f}$ ) in deciding the optimal temperature profile.

Figure 6 shows how the values of the caprolactam conversion, $\left[C_{2}\right]_{t}$ and $t_{f}$ vary with the iteration number for $I=\left[C_{1}\right]_{t_{f}}^{2}$. Some initial instability is encountered in this numerical technique when the conversion falls, but thereafter, the conversion increases and gradually approaches the optimal value. It may be pointed out that even though the value of the objective function (conversion) shows the maximum change in the first 10 iterations, a characteristic of most first-order numerical techniques, the same is not true of $t_{f}$. Figure 7 shows similar results when $I=\left[C_{2}\right]_{t_{f}}$ for the same conditions used in generating Figure 4. The oscillations referred to in the temperature profiles in Figure 4 manifest themselves as fluctuations in the values of $\left[C_{2}\right]_{t,}, \mu_{n, t_{f}}$ and conversion in Figure 7.

A systematic parametric study was undertaken in order to find out the effect of the various computational parameters of the system. The objective function $I=\alpha_{1}\left[C_{1}\right]^{2} t_{f}$ was first investigated. The value of $\Delta t$ was increased from 0.04 to $0.05 \mathrm{~h}$, keeping all other parameters at their reference values, and identical final temperature profiles were obtained as in Figure 1. However, an increase in $\Delta t$ to $0.1 \mathrm{~h}$ led to severe numerical problems.

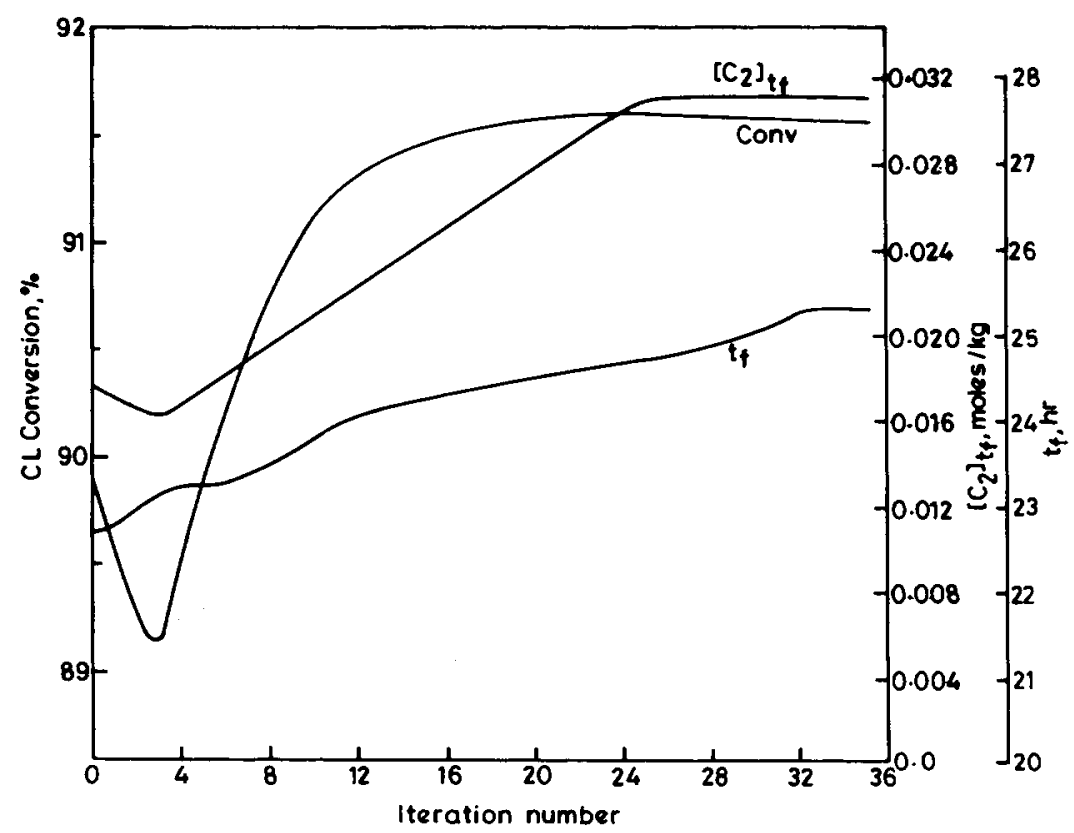

Fig. 6. Variation of $t_{f},\left[C_{2}\right]_{\ell}$, and caprolactam conversion with iteration number when $I=\left[C_{1}\right]_{t}^{2}$, Conditions as in Fig. 1 . 


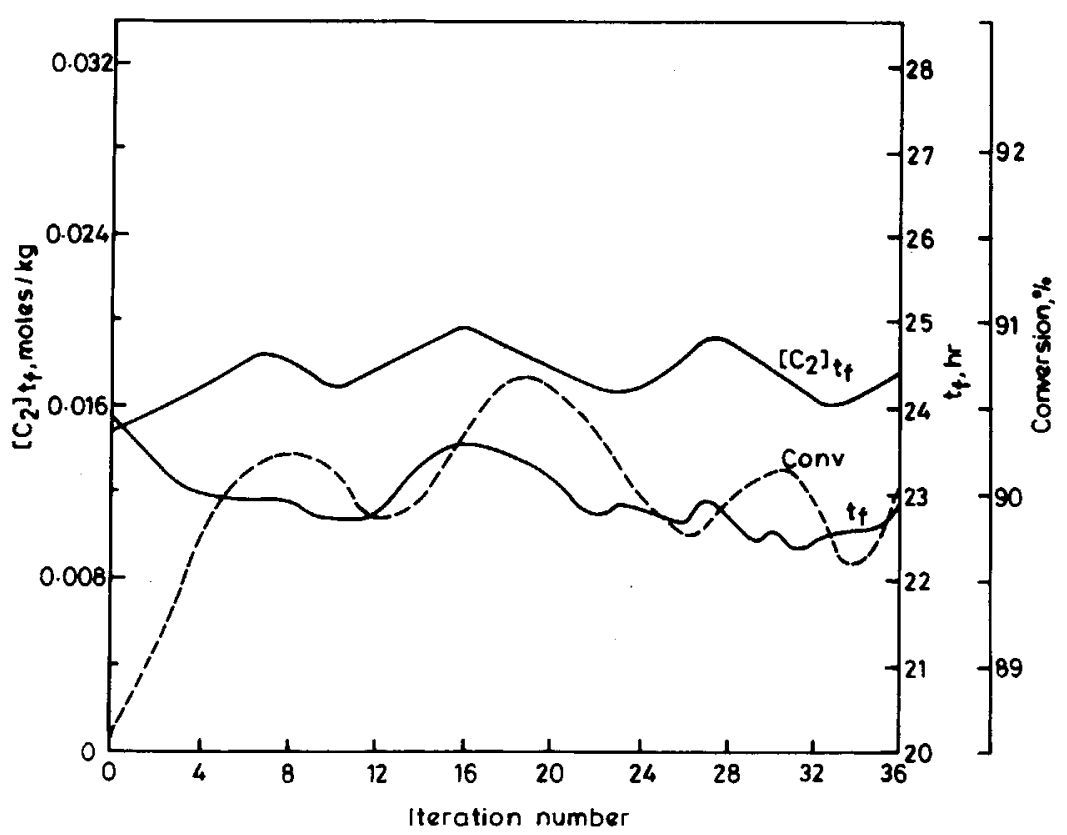

Fig. 7. Variation of $t_{f},\left[C_{2}\right]_{t_{f}}$. Same conditions as in Fig. 4.

The choice of $\Delta t$ of $0.04 \mathrm{~h}$ is thus justified. The value of $r$ [eq. (10)] was increased from the reference value of 5 to 10 , keeping all other parameters at their reference values, for this case. The final temperature profile shown in Figure 1 was again reached, but in much fewer (18) iterations compared with that (32) taken in the earlier case when $r=5$. The computer time decreased significantly to about $3 \frac{1}{2} \mathrm{~min}$. It is possible to increase $r$ to reduce the computer time and the number of iterations, but work in this direction was not pursued any further. Some computer runs were made using $\alpha_{1}=100$ [eq. (5a)] in order to see if the final results are sensitive to this parameter at all. Identical results were obtained as in Figure 1, with almost no effect on the computer time. This further confirms the correctness of our final results. The effect of the initial guess temperature profile $T_{o}(t)$ was then investigated. A uniform temperature of $245^{\circ} \mathrm{C}$ was chosen for $T_{o}(t)$ instead of the reference value of $250^{\circ} \mathrm{C}$. Identical optimal temperature profiles were obtained as in Figure 1, although about 8-10 more iterations were required. A lowering of $T_{o}(t)$ to $240^{\circ} \mathrm{C}$, however, led to a significant slowing down of the convergence when $r$ was 5 . However, when $r$ was increased to 15 , the results converged to the following optimal temperature profile: $270^{\circ} \mathrm{C}$ for $0 \leqslant t \leqslant 16.04 \mathrm{~h}$ and $220^{\circ} \mathrm{C}$ for $16.04 \leqslant t \leqslant 19.6\left(=t_{f}\right) \mathrm{h}$. This is quite different from the optimal temperature profile of Figure 1, namely, $270^{\circ} \mathrm{C}$ for $0 \leqslant t \leqslant 22.2 \mathrm{~h}$ and $220^{\circ} \mathrm{C}$ for $22.2 \leqslant t \leqslant 25.28\left(t_{f}\right) \mathrm{h}$. The difference between these two temperature profiles is attributed to the extremely slow variation of $\left[C_{1}\right]$ and $\mu_{n}$ with time (Figs. 2 and 3) near the equilibrium at $270^{\circ} \mathrm{C}$. It is expected that the agreement between these optimal temperature profiles will be far better if the value of $\epsilon_{1}$ is made smaller than 0.1. Such an interpretation is further justified by the fact that, in the case of $\mu_{n, d}=140$, where the variation of $\mu_{n}$ and [ $\left.C_{1}\right]$ with time near the 
end of the reactor is much more significant, identical final temperature profiles [of $T=270^{\circ} \mathrm{C}$ for $0 \leqslant t \leqslant 6.08\left(=t_{f}\right) \mathrm{h}$ ] are obtained, irrespective of the assumed $T_{o}(t)$. It must also be mentioned here that if $T_{o}(t)$ is chosen at $270^{\circ} \mathrm{C}$, the numerical technique used here fails since the stopping value of $\mu_{n}$ of 180 will never be attained (see Fig. 2). It is therefore required that such a guess temperature profile must be chosen that ensures the stopping condition to be met in the first iteration.

The effect of the several computational parameters of eq.(14) on the optimal temperature profile for the case $I=\left[C_{2}\right]_{t f}$ was investigated next. $T_{o}(t)$ was chosen as $250^{\circ} \mathrm{C}$ in place of the reference value of $245^{\circ} \mathrm{C}$, and the optimum temperature profile obtained was similar to that shown in Figure 4. Oscillations of the temperature profile within a $2^{\circ}$ temperature zone were once again observed. Since the initial guess for $T_{o}(t)$ is quite close to the optimal, it was found that, in this case, the convergence to the optimal zone for $T(t)$ was attained in much fewer iterations than when $T_{o}(t)$ was $245^{\circ} \mathrm{C}$. In fact, the reference value of $T_{o}(t)=245^{\circ} \mathrm{C}$ was selected specifically so that some variation of $T(t)$ is observed with iteration number in Figure 4. When $\Delta t$ was reduced from the reference value of $0.04 \mathrm{~h}$ to $0.02 \mathrm{~h}$, almost identical results were obtained for $T(t)$, although the computation time increased to about $10 \mathrm{~min}$. This suggests that the oscillations in the optimal $T(t)$ are not because of using inappropriately high values of $\Delta t$. An increase in $r$ from 5 to 8 led to considerably larger oscillations in $T(t)$ with iteration number, and in fact, it was difficult to converge to the optimal zone. A reduction in $r$ from 5 to 3 , however, led to the same final optimal temperature zone, as shown in Figure 4, with oscillations of about $2^{\circ}$ in the temperature profile versus iteration number plot. The value of $\alpha_{2}$ was also increased from 1 to 100 , and there was no effect on the results, as expected.

The influence of various physical variables given in eq. (13) was investigated next. This was done for the objective function $I=\left[C_{1}\right]_{t_{f}}^{2}$ first. All parameters except the one under study were kept at the reference values given in eqs. (13) and (14). The first variable to be studied was $\mu_{n, d}$. Figure 8 shows the details of the optimal temperature profiles obtained, and Table III lists the conditions at the output of the reactor. As mentioned earlier, the highest permissible temperature of $270^{\circ} \mathrm{C}$ was obtained over the entire reactor length for several values of $\mu_{n, d}$. This is consistent with the behavior shown in Figure 2. However, when $\mu_{n, d}$ exceeds about 167 (the equilibirium value corresponding to a reactor run isothermally at $270^{\circ} \mathrm{C}$ ), the temperature must be lowered somewhere near the end of the reactor in order to attain the desired $\mu_{n d d}$. The extreme sensitivity of the value of $t_{f}$ to $\mu_{n, d}$ may be noted above $\mu_{n, d} \simeq 167.0$. This has interesting ramifications in terms of reactor strategies. In view of the drastic increase in $t_{f}$ when $\mu_{n, d} \geqslant 167$, it may be more desirable to carry out further polymerization under solidstate conditions, possibly in heated drum-type reactors with vacuum applied.

The effect of $[W]_{o}$ on the optimal temperature profile is shown in Figure 9. Once again, similar temperature profiles are observed as in Figure 8. Table III (run numbers 9-15) shows the conditions at the end of the reactor for these conditions. It is interesting to observe that, as we increase [ $W]_{o}$, the value of $t_{f}$ required to attain $\mu_{n, d}=180$ increases significantly, even 


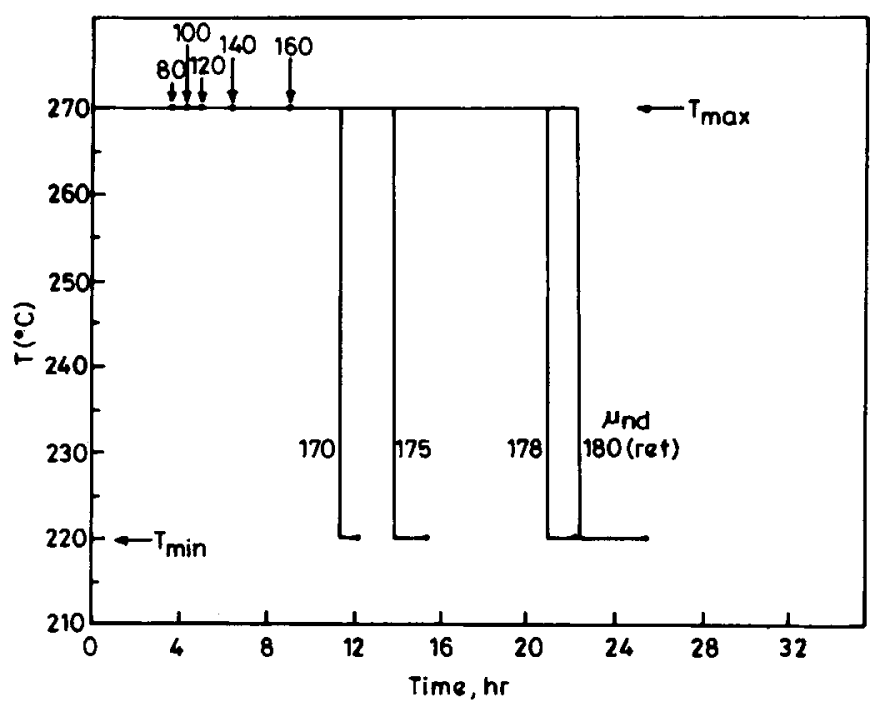

Fig. 8. Optimal temperature profiles for various values of $\mu_{n, d}$ for $I=\left[C_{1}\right]_{i_{f}}^{2}$. All other variables at their reference values. Arrows indicate $t_{f}$ for values of $\mu_{n, d}$ marked.

though the reaction is speeded up initially. It may be emphasized that the monomer conversion varies over a significant range of about $82-92 \%$ even though the degree of polymerization is the same for all cases $(=180)$. Once again, the use of $[W]_{o}$ above about $0.15 \mathrm{~mol} / \mathrm{kg}$ can be questioned for the production of polymer of $\mu_{n}=180$. It is known that the addition of small amounts of monofunctional acid $\left(A_{1}\right)$ to the feed suppresses the value of $\mu_{n}$ while simultaneously speeding up the reaction. The optimal temperature

TABLE III

Values of $\left[C_{2}\right]_{t_{f}},\left[C_{1}\right]_{t,} t_{f}, \mu_{n, d}$ for $I=\left[C_{1}\right]_{t_{f}}^{2}$

\begin{tabular}{lccccc}
\hline Run No. & $\mu_{n, d}$ & $\begin{array}{c}{[\mathrm{W}]_{o}} \\
(\mathrm{~mol} / \mathrm{kg})\end{array}$ & \multicolumn{1}{c}{$t_{f}(\mathrm{hr})$} & $\begin{array}{c}\left(1-\left[C_{1}\right]_{t f} /\left[C_{1}\right]_{o}\right) \\
\times 100(\%)\end{array}$ & {$\left[C_{2}\right]_{t_{f}}(\mathrm{~mol} / \mathrm{kg})$} \\
\hline 1 & 80 & 0.16 & 3.52 & 49.10 & 0.0043 \\
2 & 100 & 0.16 & 4.20 & 62.40 & 0.0071 \\
3 & 120 & 0.16 & 4.88 & 71.30 & 0.0093 \\
4 & 140 & 0.16 & 6.16 & 77.71 & 0.0116 \\
5 & 160 & 0.16 & 8.84 & 87.20 & 0.0174 \\
6 & 170 & 0.16 & 12.12 & 89.76 & 0.0207 \\
7 & 175 & 0.16 & 15.36 & 90.87 & 0.0238 \\
8 & 178 & 0.16 & 22.12 & 91.49 & 0.0293 \\
9 (ref.) & 180 & 0.16 & 25.28 & 91.60 & 0.0310 \\
10 & 180 & 0.12 & 9.72 & 82.24 & 0.0142 \\
11 & 180 & 0.13 & 10.44 & 85.20 & 0.0159 \\
12 & 180 & 0.14 & 12.04 & 88.67 & 0.0191 \\
13 & 180 & 0.15 & 16.00 & 90.80 & 0.0239 \\
14 & 180 & 0.155 & 17.56 & 91.15 & 0.0252 \\
15 & 180 & 0.165 & 29.76 & 91.89 & 0.0331 \\
$16^{\mathrm{a}}$ & 180 & 0.16 & 26.84 & 91.64 & 0.0317 \\
$17^{\mathrm{a}}$ & 100 & 0.16 & 3.72 & 66.972 & 0.0083 \\
\hline
\end{tabular}

${ }^{\mathrm{a}}\left[A_{1}\right]_{\mathrm{o}}=0.0005$ (run 16); $0.01 \mathrm{~mol} / \mathrm{kg}$ (run 17). 


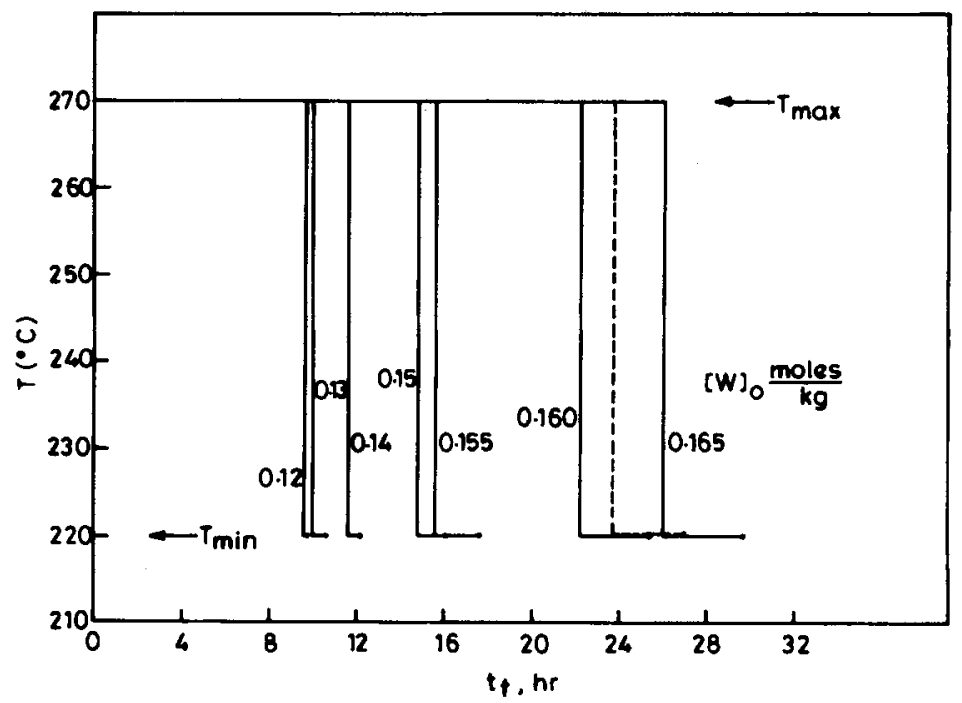

Fig. 9. Optimal temperature profiles for various values of $[W]_{0}$ for $I=\left[C_{1}\right]_{t}^{2}$ (solid). Dotted line shows optimal temperature profiles for $\left[A_{1}\right]_{o}=0.0005 \mathrm{~mol} / \mathrm{kg}$.

profile obtained with $\left[A_{1}\right]_{o}=0.0005 \mathrm{~mol} / \mathrm{kg}$ has a similar shape as the reference condition and is shown in Figure 9. Higher values of $t_{f}$ are obtained (run 16, Table III) than for the reference run, although the values of the final monomer conversion and cyclic dimer concentration are almost the same. It is obvious that the use of monofunctional acids in the feed is not recommended for obtaining high-molecular-weight polymer. It is, however, expected that the addition of $A_{1}$ to the feed will be beneficial if $\mu_{n d}$ is lower. Run 17 (Table III) shows results with $\left[A_{1}\right]_{o}=0.01 \mathrm{~mol} / \mathrm{kg}$, with $\mu_{n, d}=100$, and a comparison with results for run 2 clearly establishes the beneficial effect of adding monofunctional acid to the feed-the $t_{f}$ is reduced and the final monomer conversion is increased. The optimal temperature profile is constant at $270^{\circ} \mathrm{C}$ for $0 \leqslant t \leqslant t_{f}$.

The effect of the operating variables for $I=\left[C_{2}\right]_{t}$ is now studied. Figure 10 shows the optimal temperature profiles for various values of $\mu_{n, d}$. The maximum permissible temperature of $270^{\circ} \mathrm{C}$ throughout the reactor is predicted when $\mu_{n, d}$ is below about 167. A study of Figure 5 shows that for such cases, if one were to choose a lower temperature, the residence time $t_{f}$ required to give $\mu_{n, d}$ increases, thereby leading to an increase in $\left[C_{2}\right]_{t}$, and so is not optimal. However, at values of $\mu_{n, d}$ of above about 167, lower temperatures are predicted so that $\mu_{n, d}$ can be attained. The sharp differences with respect to the profiles of Figure 8 , for $I=\left[C_{1}\right]_{t_{f}}^{2}$ must be noted for such conditions. It may be added that the profiles plotted in Figure 10 are average values, since fluctuations of about $2^{\circ} \mathrm{C}$ with iteration number were observed in all the cases (except when $T=270^{\circ} \mathrm{C}$ throughout). Figure 11 shows similar results when $[W]_{0}$ is varied. Again, the qualitative differences with respect to Figure 9 are to be noted. Table IV gives the conditions of the product under optimal conditions for this objective function. The effect of $\left[A_{1}\right]_{0}$ on the optimal profile is shown in Figure 11 for 


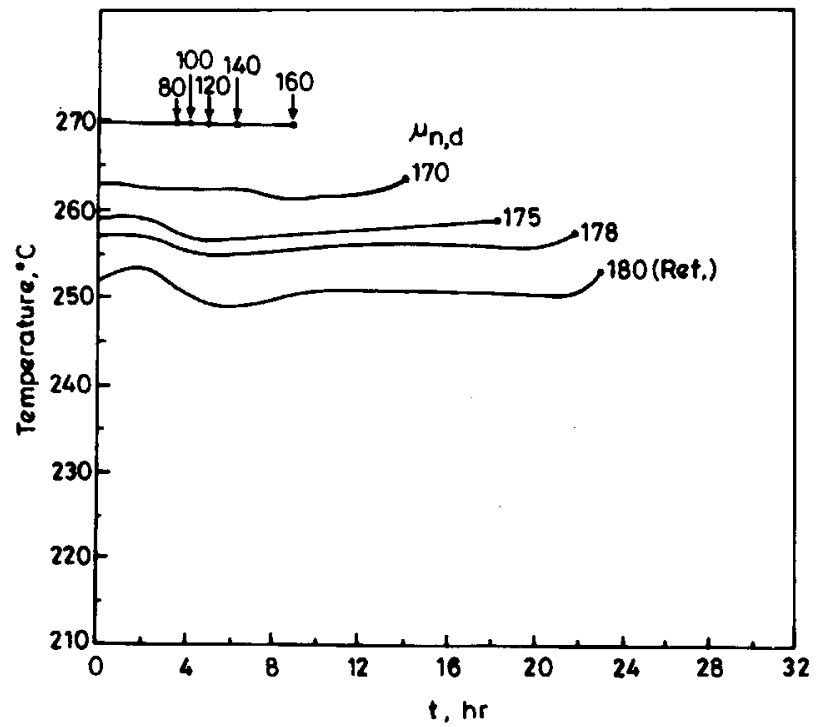

Fig. 10. Optimal temperature profiles for various values of $\mu_{n, d}$ for $I=\left[C_{2}\right]_{t_{f}}$. Arrows indicate $t_{f}$ for values of $\mu_{n, d}$ marked.

$\mu_{n, d}=180$. Once again, a significant increase in the value of $t_{f}$ is observed, with a higher monomer conversion as well as a higher value of $\left[C_{2}\right]_{t f}$ (run 15 , Table IV) when $\left[A_{1}\right]_{o}$ is $0.0005 \mathrm{~mol} / \mathrm{kg}$ and $\mu_{n, d}$ is 180 . However, when $\mu_{n, d}$ is lower (100), the optimal temperature profile is uniform at $270^{\circ} \mathrm{C}$ for $0 \leqslant t \leqslant 3.72 \mathrm{~h}$. Table IV (run 16) shows how, for these lower values of $\mu_{n, d}$, addition of monofunctional acid to the feed leads to a lower value of $t_{f}$

TABLE IV

Values of $\left[C_{2}\right]_{t f},\left[C_{1}\right]_{t f}, t_{f}, \mu_{n, d,}$ and $[\mathrm{W}]_{o}$ for $I=\left[C_{2}\right]_{t_{f}}$

\begin{tabular}{lccccc}
\hline Run No. & $\mu_{n, d}$ & $\begin{array}{c}{[W]_{o}} \\
(\mathrm{~mol} / \mathrm{kg})\end{array}$ & $t_{f},(\mathrm{hr})$ & $\begin{array}{c}\left(1-\left[C_{1}\right]_{t f} /\left[C_{1}\right]_{0}\right) \\
(\%)\end{array}$ & $\begin{array}{c}{\left[C_{2}\right]_{{ }_{f}}} \\
(\mathrm{~mol} / \mathrm{kg})\end{array}$ \\
\hline 1 & 80 & 0.16 & 3.52 & 49.10 & 0.0043 \\
2 & 100 & 0.16 & 4.20 & 62.40 & 0.0071 \\
3 & 120 & 0.16 & 4.88 & 71.30 & 0.0093 \\
4 & 140 & 0.16 & 6.16 & 77.71 & 0.0116 \\
5 & 160 & 0.16 & 8.84 & 87.20 & 0.0174 \\
6 & 170 & 0.16 & 13.92 & 89.57 & 0.0189 \\
7 & 175 & 0.16 & 18.04 & 90.06 & 0.0190 \\
8 & 178 & 0.16 & 21.68 & 90.16 & 0.0192 \\
$9($ ref.) & 180 & 0.16 & 22.40 & 90.18 & 0.0178 \\
10 & 180 & 0.12 & 9.68 & 82.78 & 0.0140 \\
11 & 180 & 0.13 & 10.6 & 86.26 & 0.0169 \\
12 & 180 & 0.14 & 14.0 & 90.02 & 0.0221 \\
13 & 180 & 0.15 & 17.64 & 89.73 & 0.0193 \\
14 & 180 & 0.155 & 20.04 & 90.35 & 0.0182 \\
$15^{\mathrm{a}}$ & 180 & 0.16 & 25.64 & 91.32 & 0.0207 \\
$16^{\mathrm{a}}$ & 100 & 0.16 & 3.72 & 66.97 & 0.0083 \\
\hline
\end{tabular}

[ $\left[A_{1}\right]_{o}=0.0005$ for run 15 and $0.01 \mathrm{~mol} / \mathrm{kg}$ for run 16 . 


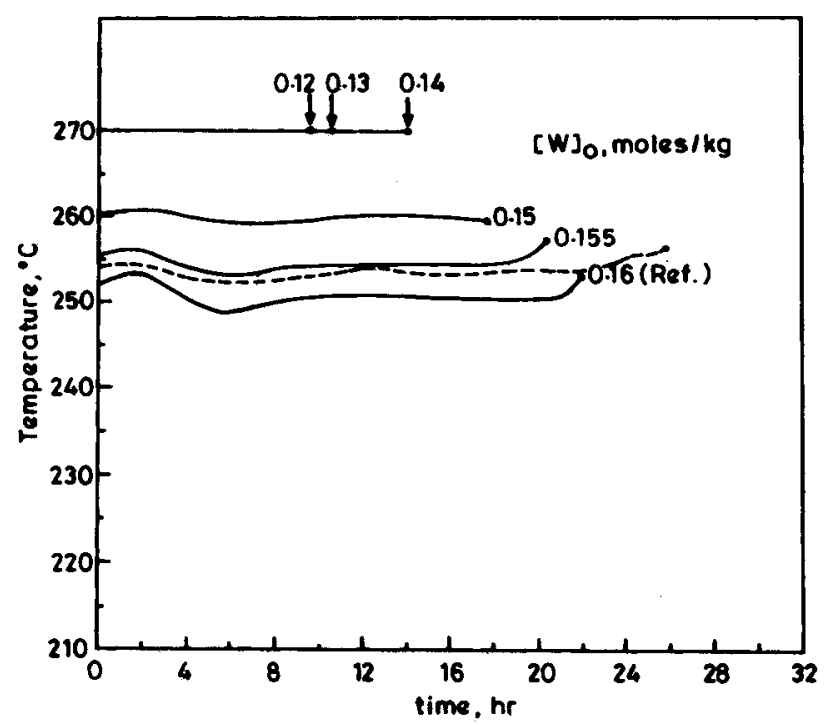

Fig. 11. Optimal temperature profiles for various values of $[W]_{o}$ for $I=\left[C_{2}\right]_{t_{f}}$ (solid). Dotted line shows profile for $\left[A_{1}\right]_{o}=0.0005 \mathrm{~mol} / \mathrm{kg}$.

(compared with run 2) but a higher value of $\left[C_{2}\right]_{t}$ as well as the monomer conversion. Evidently, minimization of $t_{f}$ dominates the value of $\left[C_{2}\right]_{t_{f}}$

It is interesting to compare the present results for $I=\left[C_{1}\right]_{t}^{2}$ with the semiquantitative results of Hoftyzer et al., ${ }^{27}$ which is the only optimization study reported with $t_{f}$ obtained optimally. The present results with a single control variable indicate a bang-bang type of temperature policy. In contrast, Hoftyzer et al., who use two control variables, $T$ and $[W]$, obtain temperature profiles given by $T=T_{\max }$ for some time, after which the $T$ falls gradually. It is thus observed that the use of $[W]$ as an additional control variable leads to qualitatively different optimal temperature profiles. No such comparison with earlier results is possible for the second problem, $I=\left[C_{2}\right]_{t}$, solved in this paper.

\section{CONCLUSIONS}

An optimization study for nonvaporizing plug-flow (or batch) Nylon 6 reactors has been presented, using the most recent kinetic information available on the main and side reactions. The major difference from our own earlier optimization studies, ${ }^{25,26}$ as well as those of Naudin ten Cate ${ }^{24}$ and Mochizuki and Ito, ${ }^{23}$ is in treating the residence or reaction time $t_{f}$ as a variable, instead of it being specified a priori. This makes the algorithm far more complicated. It is hoped that the experience gained with this study will be useful in overcoming problems encountered while developing algorithms for more meaningful, complex, and more general optimization problems for nonvaporizing reactors. 


\section{References}

1. J. A. Biesenberger and D. H. Sebastian, Principles of Polymerization Engineering, Wiley, New York, 1983.

2. M. V. Tirrell and R. L. Laurence, Polym. React. Eng., in preparation.

3. W. H. Ray and R. L. Laurence, in Chemical Reactor Theory, L. Lapidus and N. R. Amundson (eds.), Prentice-Hall, Englewood Cliffs, New Jersey, 1977.

4. S. K. Gupta and A. Kumar, Reaction Engineering of Step Growth Polymerization, Plenum Press, New York, in press.

5. H. K. Reimschuessel, in Ring Opening Polymerization, K. C. Frisch and S. L. Reegen, (eds.), Marcel Dekker, New York, 1969.

6. H. K. Reimschuessel, J. Polym. Sci., Macromol. Rev., 12, 65 (1977).

7. J. Śbenda, Prog. Polym. Sci., 6, 123 (1978).

8. K. Tai and T. Tagawa, Ind. Eng. Chem., Prod. R\&D, 22, 192 (1983).

9. A. Kumar and S. K. Gupta, J. Macromol. Sci., Rev. Macromol. Phys. Chem., in press.

10. H. K. Reimschuessel and K. Nagasubramanian, Chem. Eng. Sci., 27, 1119 (1972).

11. K. Tai, H. Teranishi, Y. Arai, and T. Tagawa, J. Appl. Polym. Sci., 24, 211 (1979).

12. K. Tai, H. Teranishi, Y. Arai, and T. Tagawa, J. Appl. Polym. Sci., 25, 77 (1980).

13. Y. Arai, K. Tai, H. Teranishi, and T. Tagawa, Polymer, 22, 273 (1981).

14. K. Tai and T. Tagawa, J. Appl. Polym. Sci., 27, 2791 (1982).

15. M. V. Tirrell, G. H. Pearson, R. A. Weiss, and R. L. Laurence, Polym. Eng. Sci., 15, 386 (1975).

16. K. Nagasubramanian and H. K. Reimschuessel, J. Appl. Polym. Sci., 17, 1663 (1973).

17. K. Nagasubramanian and H. K. Reimschuessel, J. Appl. Polym. Sci., 16, 929 (1972).

18. K. Tai, Y. Arai, and T. Tagawa, J. Appl. Polym. Sci., 27, 731 (1982).

19. K. Tai, Y. Arai, and T. Tagawa, J. Appl. Polym. Sci., 28, 2527 (1983).

20. S. K. Gupta, A. Kumar, and K. K. Agarwal, J. Appl. Polym. Sci., 27, 3089 (1982).

21. S. K. Gupta, D. Kunzru, A. Kumar, and K. K. Agarwal, J. Appl. Polym. Sci., 28, 1625 (1983).

22. H. Jacobs and C. Schweigman, Proc. 5th Eur./2nd Intl. Symp. Chem. Rxn. Eng., Amsterdam, 2-4 May, 1972, pp. B7.1.

23. S. Mochizuki and N. Ito, Chem. Eng. Sci., 33, 1401 (1978).

24. W. F. H. Naudin ten Cate, Proc. Internl. Cong. Use of Elec. Comp. in Chem. Eng., Paris, April 1973.

25. A. Ramagopal, A. Kumar, and S. K. Gupta, J. Appl. Polym. Sci., 28, 2261 (1983).

26. S. K. Gupta, B. S. Damania, and A. Kumar, J. Appl. Polym. Sci., 29, 2177 (1984).

27. P. J. Hoftyzer, J. Hoogschagen, and D. W. van Krevelen, Proc. 3rd Eur. Symp. Chem.

Rxn. Eng., Amsterdam, 15-17 Sept. 1964, p. 247.

28. Germ. Patent, 1167021 (1962), Vereinigte Glanzstoff Fabriken.

29. K. Tai, Y. Arai, H. Teranishi, and T. Tagawa, J. Appl. Polym. Sci., 25, 1789 (1980).

30. A. Ramagopal, A. Kumar, and S. K. Gupta, Polym. Eng. Sci., 22, 849 (1982).

31. S. K. Gupta, A. Kumar, P. Tandon, and C. D. Naik, Polymer, 22, 481 (1981).

32. S. K. Gupta, C. D. Naik, P. Tandon, and A. Kumar, J. Appl. Polym. Sci., 26, 2153 (1981).

33. L. Lapidus and R. Luus, Optimal Control of Engineering Processes, Blaisdell Pub. Co., Waltham, Massachusetts, 1967.

34. A. E. Bryson and Y.C. Ho, Applied Optimal Control, Blaisdell, Waltham, Massachusetts, 1969.

35. M. M. Denn, Optimization by Variational Methods, McGraw-Hill, New York, 1969. 